\section{Richard Colombo}

is an associate professor of marketing at Fordham University Graduate School of Business. He has an MA from Cambridge University and an $M B A$ and PhD from Columbia University.

Keywords: Web metrics, stochastic models
Richard Colombo,

Fordham University,

113 W 60 St, New York 10023

USA

Tel: 12038610075

Fax: 12036250133

E-mail: rcolombo@pipeline.com;

richard.colombo@verizon.net

\section{Visitor patterns of a profitable website}

\author{
Richard Colombo
}

Received (in revised form): 11 May 2001

\begin{abstract}
The vast quantities of data generated from Web log files are a mixed blessing for marketers. On the one hand, they offer unprecedented opportunity to learn about customers and customise marketing programmes, but on the other hand they pose considerable difficulties for extracting relevant information. Well-defined metrics backed up by sound theoretical models and exploratory visualisation tools provide a way for managers to learn about their customers from records of their Web visits.
\end{abstract}

\section{Introduction}

E-businesses routinely record the activity of visitors to their websites. Every page view is recorded, every click leaves a trace. In theory, these 'footprints in the sand' offer marketers an unprecedented opportunity to learn about their customers. In practice, the result is often an overwhelming flood of data.

Compared to bricks-and-mortar retailers, where only purchases are easily observable, online retailers are able to capture and analyse visiting patterns and transactions to gain a better understanding of their customers. The availability of these kinds of data puts online retailers in a better position to realise the benefits of customer relationship management (better targeting, higher levels of customer service and satisfaction, reduced customer attrition, etc) than their offline counterparts. It has been estimated that there are now over 500 vendors offering CRM software to help online retailers take advantage of the opportunities offered by this data glut, and that e-CRM software market will grow to top $\$ 11 \mathrm{bn}$ in sales in the USA alone by $2003 .{ }^{1}$

Notwithstanding the large number of 'solutions' on offer, the promise of customer Web data is offset by unique characteristics that present challenges to marketers.

The most obvious characteristic of Web data is their quantity. Server $\log$ files record every click and every element of every viewed page. A Web page with many graphic elements (usually gif files) will therefore populate the log files with many entries that are of no value to marketers. To be useful, server log files need to be pre-processed not only by removing useless data but also by identifying key events of interest (such as a click on a picture of a product to see a larger view), 'sessionising' the data (grouping together activities into a session) and linking visits to users (through the use of cookies, for example). Even after pre-processing, the data files remain immense. 


\section{Consumer behaviour and online shopping}

\section{Web metrics}

Essential to CRM-like initiatives are individual-level data, which means that visitors must be tracked over time. The use of cookies makes this easy, but many computer users do not allow cookies and many of those who do delete them periodically. The result is that the marrying of visits to visitors is not perfect and that data quality is not what it ought to be. Nonetheless, some data, carefully used, are better than no data.

Most websites know only about visits to their sites and are ignorant of what other sites were visited. This is also true of offline businesses. However, in some industries, for example the grocery industry, market research companies such as IRI and Nielsen use consumer panels to track purchases. Consumer panels record information about brand purchases and store visits and about the purchase environment. From these panels, marketers know not just about the price, say, of the brand that was bought but also about the prices in the store of all the competing brands that were not bought. This information has been enormously useful to manufacturers and retailers, but little of this kind of information is available about online visits and purchases.

In addition to differences in the kinds of data available to online and offline businesses, there are also differences in consumer behaviour that raise challenges for marketers. One key difference is that search costs are lower in the online world. This alone is probably a major reason why only about 3 per cent of online shoppers end up making a purchase compared with about 40 per cent of prospective customers at offline stores. ${ }^{2}$ There are other reasons, of course, such as concern about the privacy/security of buying via an unfamiliar channel, the difficulty of navigating to an appropriate page (one well-known website had 47,000 pages, of which 44,000 were not accessed in a typical month), slow server response, etc. Low search costs imply that online retailers need to lower the price consciousness of online customers by differentiating their sites and providing some benefits that 'lock in' their customers. ${ }^{3}$ Amazon.com with its easily navigable site, one-click shopping, sensible recommendations based on a collaborative filtering algorithm and ability to save shopping carts and wish lists provides a good example.

Another challenge to marketers is what to measure. To make sense of data from website log files requires that the data be summarised or reduced to a manageable form. Through experience, traditional offline businesses have developed many useful summary measures - metrics that they use to understand and manage their activities. Price-earnings ratio, market share and revenues per customer are just three familiar and time-tested examples.

In the online world, there is less agreement about what metrics are, or will prove to be, useful in understanding user activities at websites. Page hits, unique visitors, duration and click-through are some commonly reported metrics but there are many more.

A significant issue for online retailers is, therefore, what exactly should be measured? Is it page hits per month, time spent on a page, number of unique visitors or one of the many other measures that have been proposed? And how should the measures be interpreted? It seems that most online retailers gather and use data at the aggregate level. However, 
consumer activity tracked at the individual level yields far richer insights than aggregate data can possibly provide.

Uncertainty about what should be measured stems in part from lack of a theoretical framework for how consumers behave in online stores. But there is a wealth of knowledge and theory about how consumers behave in the offline world and there is good reason to suppose that this understanding of consumers would be relevant in the online world. It would seem, therefore, that individual-level data combined with insights from theories about how consumers behave - particularly about how they search for information and about their repeat buying behaviour can offer a fruitful way of understanding online activity. In other words, instead of merely reporting aggregate statistics of online activity as is now commonly done, data-based (statistical) models of consumer activity can be built to provide insight into consumer online activity and serve as decision aids for marketing managers.

This paper explores some ways of making sense of data generated from websites. Two examples will be given. The first is a simple example that shows some plots of patterns in Web data. The second shows the value of formal modelling.

\section{Unique visitors and durations}

The first example is taken from data produced by Nielsen/Netratings on the number of unique visitors to a website and the time they spend at the site for the top 50 sites in each week for nine months. The Nielsen data measure the visits of a panel of consumers to any website, in contrast to log-file data that measure activity within a site. The Nielsen data therefore give a broad-brush overview of 'market structure'. Figure 1 shows the

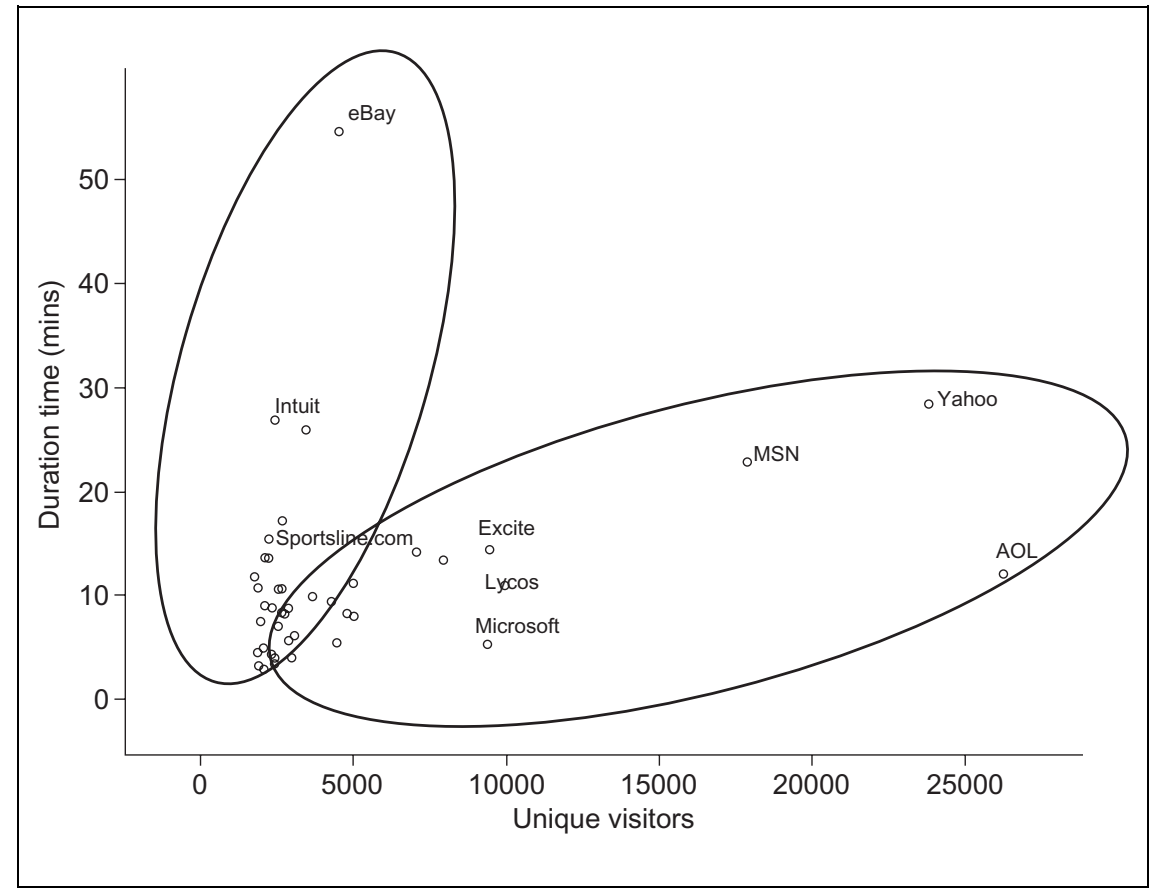

Figure 1: Number of unique visitors and time spent for largest websites 

There are two broad
types of websites average duration plotted against average number of weekly unique visitors. Figures 2 and 3 shows the marginal distributions. Three features stand out:

- the distribution of the number of unique visitors is highly skewed (Figure 1)

- duration times are also skewed (Figures 2 and 3)

- there seems to be a correlation between number of unique visitors and duration (Figure 1).

Figure 1 shows that there seem to be two groups among the leading websites - those that attract a large number of visitors whose visit duration is relatively low and those that attract a few visitors who stay a while. In the former group are sites such as AOL and Yahoo, which provide a lot of content and have established themselves as portals. EBay, on the other hand, provides a service for buyers and sellers. Anyone using this site is likely to check back often to see how their auction is proceeding. Financial sites are likely to be in this group, too, as are sites catering to specialised interests such as Sportsline.com.

While the data are not sufficient to draw firm conclusions, they do hint that websites are in a winner-takes-all market ${ }^{4}$ where a few large sites capture the bulk of visitors (the top three sites -6 per cent of the sites listed - have one-third of all unique visitors). A characteristic of winnertakes-all markets is that they follow a Zipf distribution. Zipf's 'law' states

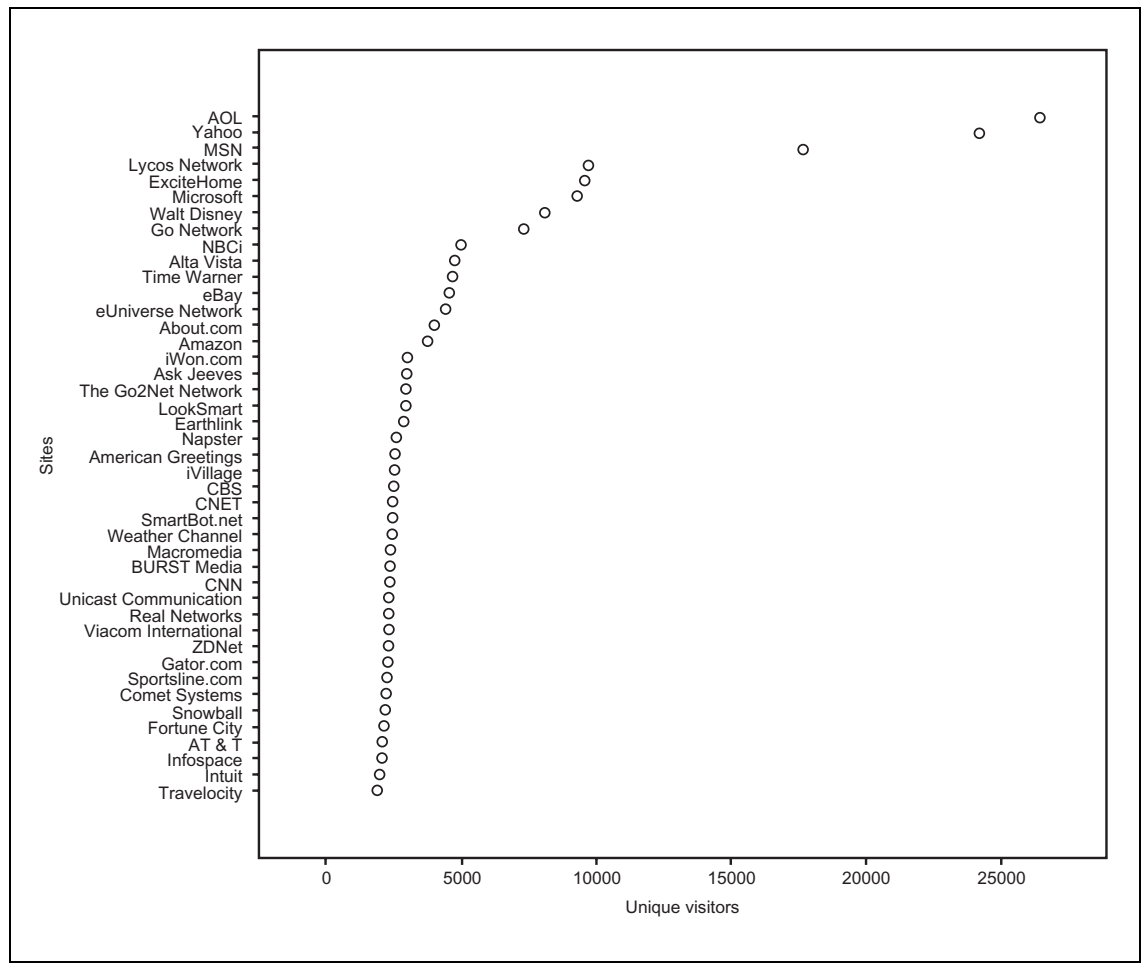

Figure 2: Average number of unique visitors per week for leading websites 


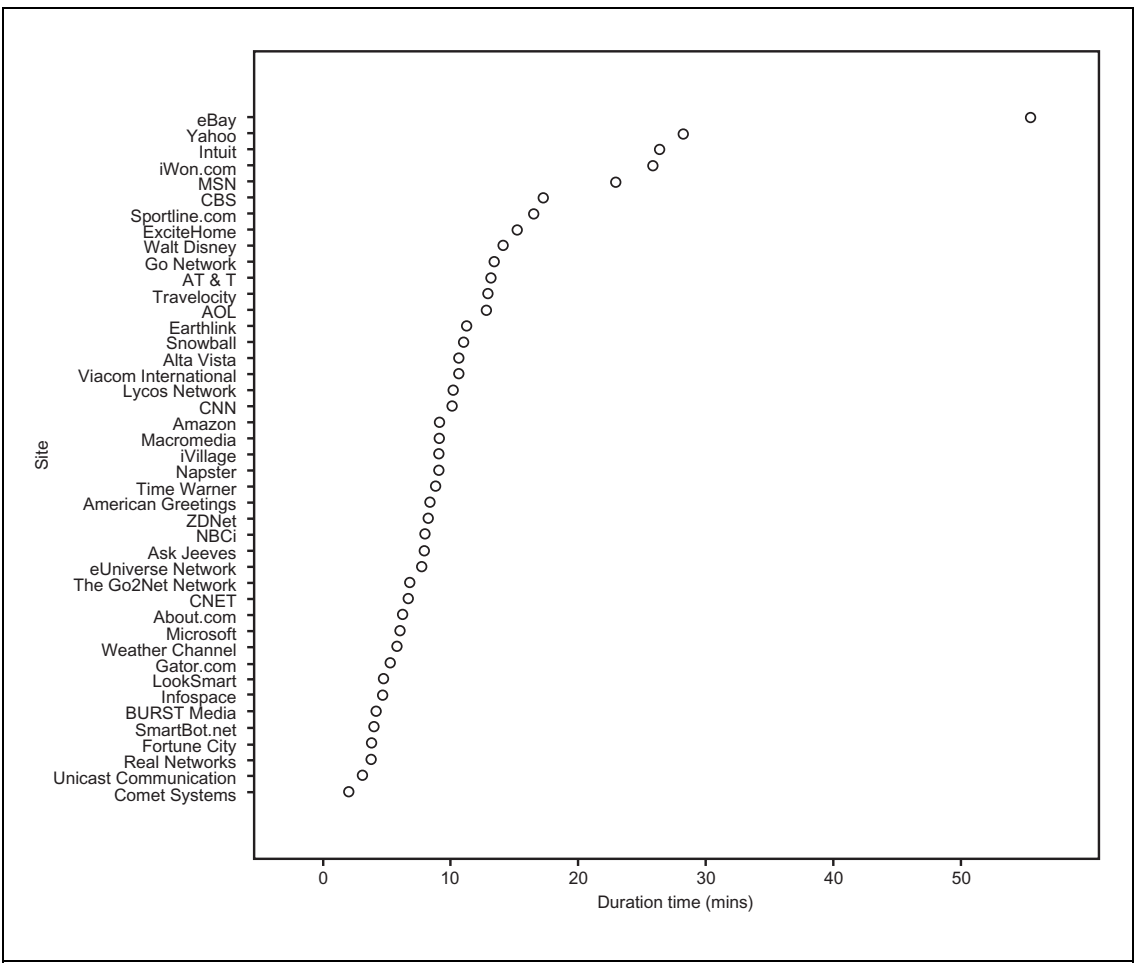

Figure 3: Average weekly duration times of visits to leading websites

that the size of an occurrence, $\mathrm{z}$ (number of unique visitors at a website), is inversely proportional to the rank, $r$, of the occurrence:

$$
z \quad r^{\ddot{y} k}
$$

where $\mathrm{k}$ is usually close to 1 . A plot of the log of the number of unique visitors against log rank in Figure 4 shows the straight line expected from a Zipf distribution. ${ }^{5}$

Loosely speaking, winner-takes-all markets ${ }^{6}$ lead businesses to maximise customer share, because in such markets the dominant business has a customer share far in excess of the number two player. To the extent that a significant source of a website's revenue comes from advertising, achieving dominance in customer share makes sense. Winner-takes-all markets also arise where there are network externalities. For example, a site such as eBay delivers greater value for buyers and sellers alike the more customers it has. And Amazon.com gains from network externalities because its recommendation system can be more finely tuned the more customers it has.

Figure 1 also shows that within each of the two groups of sites there is a correlation between unique visitors and duration times. That is, the more visitors a site has the longer they stay (or the more often they visit). This is reminiscent of the double jeopardy phenomenon, ${ }^{7,8}$ which is well known in markets of frequently purchased packaged goods. In this context, double jeopardy means that small sites suffer in two ways: fewer people visit them and those who do stay for less time. The double 


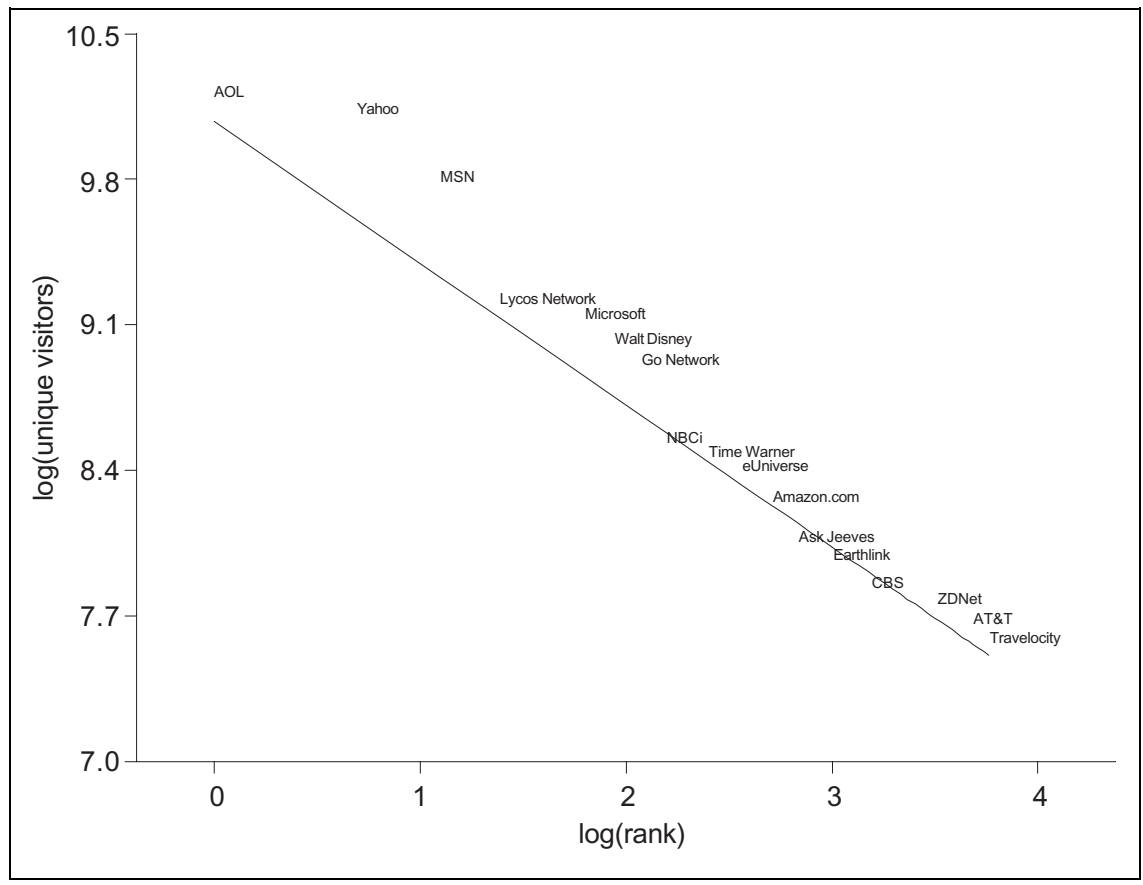

Figure 4: Zipf ranking

jeopardy phenomenon, like the winner-takes-all phenomenon, thus testifies to the advantage of having large market share. In addition, the existence of double jeopardy on the Web suggests that users' activities on websites may not be altogether different from those in arenas that are more traditional, and that established metrics and models might have a role in understanding customer behaviour in the new economy. In this regard, analogies among metrics such as penetration and average purchase frequency, ${ }^{9}$ reach and frequency ${ }^{10}$ and duration and unique visitors are worth exploring.

\section{Modelling retail growth: The case of Amazon.com}

A second example shows the benefit of basing metrics on a model or theory about the underlying process that generates the metrics.

A recent article in the New York Times ${ }^{11}$ compared two metrics with, at least superficially, very different implications. Many online retailers such as Amazon.com trumpet two measures which both increase with time: revenues and number of customers. The customer database of a firm will generally increase in size over time as new customers are added since most businesses do not eliminate customers from the database, at least in the growth stage, based on their lack of activity. However, the number of customers does not tell the whole story - repeat buying is obviously important and revenues/month is a measure of this (although it will be

How are responses per customer expected to behave over time confounded with number of customers).

Typically, then, revenues/month and number of customers will increase over time. But what if one calculates revenues/customer for each month? As the New York Times article pointed out, for many companies such as 
eBay, Amazon.com and CDNow, revenues/customer are declining and this would appear to augur ill. So is it good news that customers and revenues are increasing or is it bad news that revenues/customer are decreasing? This is obviously an important question since the business models of most online retailers require strong repeat business; understanding how revenues/customer behaves or is expected to behave over time is crucial.

Two answers to how revenue per customer behaves over time were given in the New York Times article. A spokesman for Amazon.com was reported as saying 'Not every person shops every quarter. So a steady decline is exactly what you would expect to see', while a spokesperson for eBay said, 'On average, the number is going down because not all customers stay, but the customer who is staying is spending so much more that it outweighs attrition.'

These quotes are not very enlightening. While prospects for these businesses may be dim, a decline in revenues per customer does not by itself predict gloom. In fact, revenues per customer would be expected to decline even for businesses with bright prospects. This is because the customers who enter the database early are likely to be the heavy (high repeat) buyers while those who became customers late are more likely to be light buyers. To see this, consider two individuals, one who is a heavy buyer and one who is a light buyer. When Amazon.com first came 'online' the heavy buyer would have been more likely to have learned about Amazon.com and bought from there than the lighter buyer. In Amazon.com's early days, its database would have been populated by those who were relatively heavy buyers. But over time lighter buyers would enter the database, although at a slowing rate. In this way, the database would keep growing and so would quarterly revenues, but revenues per customer would decline over time as the database becomes diluted with less valuable (light) buyers. This intuition can be given formal expression using the same assumptions that lead to the well-known negative binomial distribution (NBD) that has been found to describe many aspects of repeat buying well. ${ }^{12}$ See the Appendix for mathematical details.

Based on the model described in the Appendix, Figure 5 shows that the average purchase rate (which if purchase amounts do not vary much - as we would expect for books - can be taken as a surrogate for average revenues per customer) has a downward slope.

Thus, revenues per customer decline over time even as total revenues and the size of the customer database increase. Figure 5 is useful, too, because it predicts the long-run buying rate. If we assume that customers' buying rates do not change, the parameters of the NBD can be estimated from the buying behaviour of the early buyers and used to project the long-run buying rate to provide an early warning of the long-run health or otherwise of the business. Alternatively, the predictions from the NBD can be used as benchmarks; if the observed buying rate were substantially below the predicted buying rate, this would be a sign of customer attrition.

The NBD model above, while useful, lacks some face validity because 


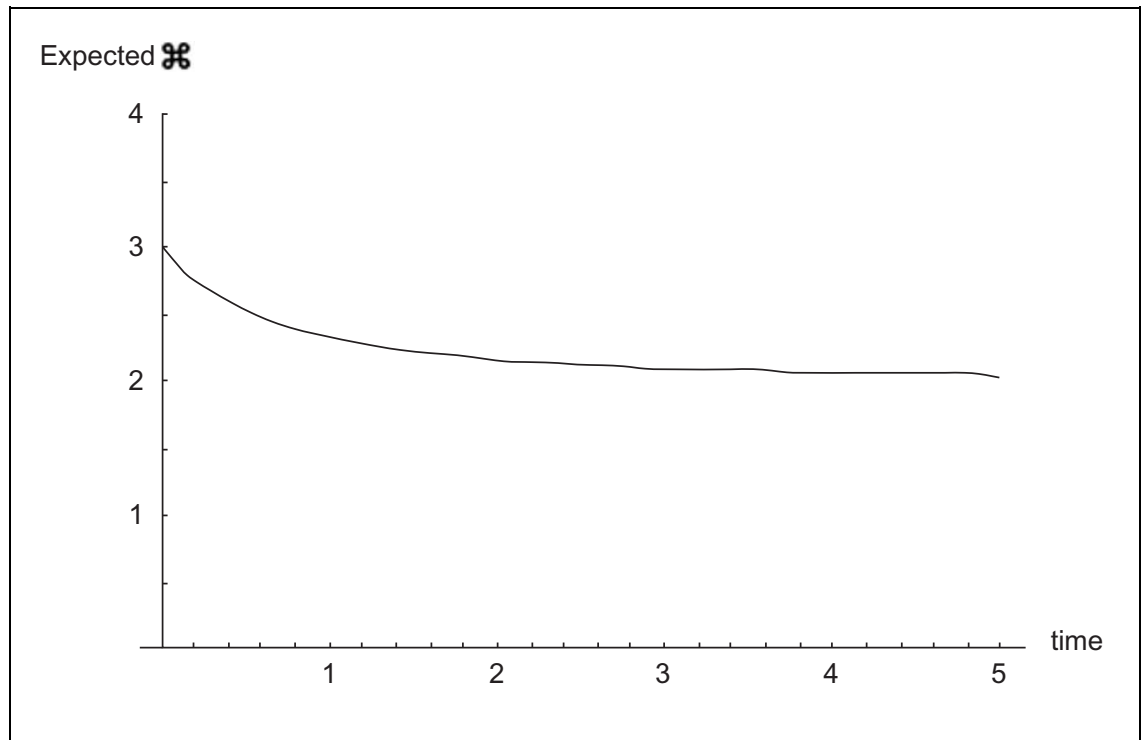

Figure 5: Average purchase rate

it predicts that the penetration curve (the percentage of buyers who bought at least once within some time period) rises rapidly at first but then levels off (ie has a convex shape). An examination of the sales curve, which will be closely related to the penetration curve, for Amazon.com or indeed most new businesses shows an S-shaped curve. The NBD can very simply be modified to produce an S-shaped curve by assuming that not everyone becomes a potential buyer of Amazon.com at the same time, as is implicitly assumed by the NBD. Specifically, a S-shaped sales curve can be generated by assuming that before someone can buy from Amazon.com they first have to learn of its existence, and that the rate at which people learn is the same as their buying rate (heavy buyers learn more quickly about a new channel than light buyers). In effect, the time at which someone becomes aware of Amazon.com is random. Details are given in the Appendix.

The sales curve as predicted from the 'random start-time' model was fitted to observed sales data for the first few years of Amazon.com's sales. The result is shown in Figure 6. The fit is reasonably good although the amount of data on sales is not sufficient to show a dramatic S-shaped effect. Since the researchers were modelling penetration but had sales figures, an additional parameter was used to represent the total market size in the fitting process. The total market size was estimated as $\$ 2.1 \mathrm{bn}$, although, as with most 'forecasts' based on a few early data points, the result should be treated with some scepticism.

The NBD model and its modification is a model of markets where consumer buying rates do not change. In the current climate of rapid growth in websites (and more recently in the decline of e-businesses), a stationary model would on the face of things not be entirely appropriate. Rather than abandon the NBD, one can modify it to allow for the evolution of repeat buying rates. For example, a consumer's buying rate at 


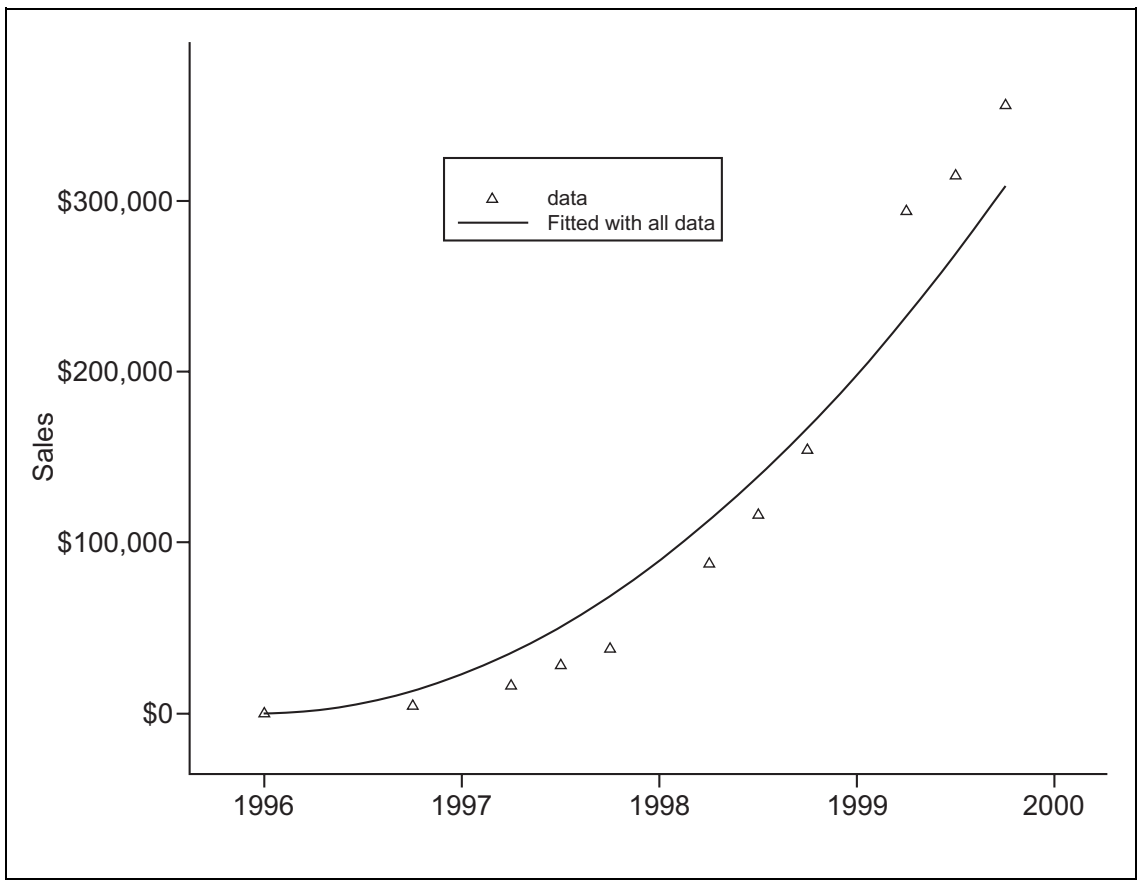

Figure 6: Predicted and observed sales for Amazon.com

a time, $t$, could be considered as a (convex) combination of a long-term buying rate and their current rate. The long-term buying rate is the rate at which a consumer ends up buying from Amazon.com after the early instability in buying behaviour brought about by the new channel settles down. This extension to the model will not be pursued here. But clearly, being able to obtain an estimate of the long-term buying rate of customers in one's database has considerable managerial usefulness.

\section{Discussion}

This paper has shown through simple visualisation that there are possibly two broad types of websites - informational/entertainment and business — and has used a well-known existing model, slightly modified, to quantify insights into the growth of an e-business. The plots in Figures 1, 2 and 3 show the situation in one period of time. It would be interesting to produce similar plots for different periods to investigate how the structure of Web markets changes over time. One might expect an increase in the penetration of the Internet to drive up the number of unique visitors, but the effect on average duration at a site is less clear. As a website grows through acquisition of other sites or the development of additional content, the number of unique visitors will also be expected to grow and the double jeopardy phenomenon predicts that average duration will also increase. What is clear from Figure 1 is that the interpretation of metrics requires that the metrics be referred to appropriate benchmarks. Whether two broad types of websites are sufficient to provide benchmarks or whether there are other ways to categorise sites would be something that needs further investigation. 
The NBD model showed how a simple model could give precision to rather vague notions about what particular metrics mean. Revenues and number of customers seem well defined, but simple derived metrics such as revenues per customer can cause confusion unless they are based on some clear view, or model, of how customers behave. Further research is needed to understand what models and model-based metrics would be helpful in tracking and diagnosing customer behaviour. Although modelling can provide quantitative predictions, the real value comes in the insights into consumer behaviour that it gives. The modelling made clear that as time passes customers who enter the database are less valuable than early customers. Therefore, spending vast quantities of money on advertising to acquire new customers is going to have diminishing payoffs over time - a lesson that now seems to have been learned by many dot.com companies.

\section{Appendix}

\section{NBD}

Assume that a customer makes purchases from Amazon.com in a Poisson fashion with parameter $\lambda$. Further assume that $\lambda$ varies from customer to customer as a gamma distribution with shape parameter $r$ and scale parameter $\alpha$.

$$
\begin{array}{rlll}
P(X \quad x \mathrm{j} \lambda, T) & \frac{(\lambda T)^{x}}{x !} e^{\ddot{y} \lambda T}, \quad x \quad & 0,1, \mathrm{~K} ; \lambda>0: \\
& g(\lambda \mathrm{j} r, \alpha) & \frac{\alpha^{r}}{\Gamma(\alpha)} \lambda^{r \ddot{y} 1} e^{\ddot{y} \alpha \lambda}, & r, \alpha>0
\end{array}
$$

These two assumptions imply that the aggregate number of purchases in time $\mathrm{T}$ is distributed as a negative binomial distribution given by:

$$
\begin{aligned}
P(X \quad x \mathrm{j} T, r, \alpha) \quad & \frac{(\lambda T)^{x}}{x !} e^{\ddot{y} \lambda T} \frac{\alpha^{r}}{\Gamma(\alpha)} \lambda^{r \ddot{y} 1} e^{\ddot{y} \alpha \lambda} \\
& \frac{\Gamma(r \quad x)}{\Gamma(\alpha) \Gamma(x \quad 1)} \frac{\alpha}{\alpha \quad T} \frac{T}{\alpha T}^{x}
\end{aligned}
$$

We can now calculate the penetration curve - the probability that at least one purchase is made by time $t$. The penetration is

$$
1 \ddot{\mathrm{y}} P(X \quad 0 \mathrm{j} r, \alpha, t) \quad 1 \ddot{\mathrm{y}} \quad{\frac{\alpha}{\alpha{ }^{r}}}^{r}
$$

and the expected value of $\lambda$ given that at least one purchase has been made by time $t$ is

$$
E[\lambda \mathrm{j} x>0] \quad \frac{r}{\alpha} \frac{1 \ddot{\mathrm{y}} \frac{\alpha}{\alpha}^{r}{ }^{1}}{1 \ddot{\mathrm{y}} \frac{\alpha}{\alpha t}}{ }^{r}
$$




\section{Modified NBD}

We will assume that the time, $\tau$, at which someone becomes a potential buyer is exponentially distributed with parameter $\lambda$, the same parameter that governs their buying rate.

$$
f(\tau) \quad \lambda e^{\ddot{y} \lambda \tau}
$$

The intuition behind this assumption is that heavy book buyers are more likely to be early customers of Amazon.com than light book buyers. With this assumption, we have that $\mathrm{t} \quad 0$ is when Amazon.com opens for business, $\mathrm{t} \quad \tau$ is when a buyer first becomes aware of Amazon.com and $\mathrm{t} \tau \mathrm{T}$ is when they make their first purchase.

We can now derive the observed penetration curve. First, note that the distribution of purchases in time $t$ for someone with buying rate $\lambda$ and who becomes aware of Amazon.com at a time given by (5) is given by a Poisson distribution but with the first event 'ignored', since this event is when the customer becomes aware.

$$
P\left(\begin{array}{ll}
X & x \mathrm{j} t
\end{array}\right) \quad \frac{(\lambda t)^{x} \quad 1}{(x \quad 1) !} e^{\ddot{y} \lambda t} \quad x \quad 1,2, \mathrm{~K}
$$

Since

$$
{ }_{x} \frac{(\lambda t)^{x} 1}{\left(\begin{array}{ll}
x & 1
\end{array}\right) !} e^{\ddot{y} \lambda t} \quad 1 \ddot{y}\left(\begin{array}{ll}
1 & \lambda t
\end{array}\right) e^{\lambda t},
$$

it follows that the penetration is

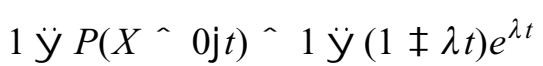

If we now allow $\lambda$ to vary as a gamma(r, $\alpha)$ we have

$$
P(X \quad 0 \mathrm{j} t, r, \alpha) \quad{ }_{0}^{1}(1 \quad \lambda t) e^{\ddot{y} \lambda t} \frac{\alpha^{r}}{\Gamma(\alpha)} \lambda^{r \ddot{y} 1} e^{\ddot{y} \alpha \lambda} d \lambda
$$

so that the penetration is

$$
\ddot{\mathrm{y}}{\frac{\alpha}{\alpha r^{\prime}}}^{r} 1 \frac{r}{\alpha} t \frac{\alpha}{\alpha}
$$

A plot of this penetration curve shows an S-shape. Analogous to (4), the expected value of the buying rate under this 'random start-time' model can be derived and has the same downward sloping shape as in Figure 5.

\section{References}

1. ebusiness.com (2001) The Economist Intelligence Unit, April.

2. Ibid.

3. Mahajan, Vijay and R. Venkatesh (2000) 'Marketing modelling for e-business', International Journal of Research in Marketing, No. 17, pp. 215-225.

4. Adamic, Lada and Bernardo Huberman (2000) 'The nature of markets in the World Wide Web', Quarterly Journal of Electronic Commerce, Vol. 1, No. 1, pp. 5-12.

5. Nielsen, Jakob (1997) Do Websites Have Increasing Returns?, www.useit.com/alertbox/9704b.html.

6. Frank, Robert and Philip Cook (1995) The Winner-take-all Society, New York, Free Press. 
7. Ehrenberg, Andrew S. C., Goodhardt, Gerald J. and Barwise, T. Patrick (1990) 'Double jeopardy revisited', Journal of Marketing, No. 54, July, pp. 82-91.

8. Ehrenberg, Andrew S. C. (1988) Repeat Buying: Facts, Theory, and Applications, London, Charles Griffin and Co., New York, Oxford University Press.

9. Ibid.

10. Rust, Roland T. (1986) Advertising Media Models: A Practical Guide, Lexington, MA, Lexington Books.

11. Kaufman, Leslie (1999) 'Cutting through fog of growth for Net retailers', New York Times, 1 September.

12. Ehrenberg, ref. 8 above. 